\title{
Beckmann Rearrangement of Cyclotriveratrylene (CTV) Oxime: Tandem Beckmann-Electrophilic Aromatic Addition
}

\author{
Marlon R. Lutz Jr. \\ Loyola University Chicago \\ Matthias Zeller \\ Daniel P. Becker \\ Loyola University Chicago, dbecke3@luc.edu
}

Follow this and additional works at: https://ecommons.luc.edu/chemistry_facpubs

Part of the Chemistry Commons

Author Manuscript

This is a pre-publication author manuscript of the final, published article.

\section{Recommended Citation}

Lutz, Marlon R. Jr.; Zeller, Matthias; and Becker, Daniel P.. Beckmann Rearrangement of Cyclotriveratrylene (CTV) Oxime: Tandem Beckmann-Electrophilic Aromatic Addition. Tetrahedron Letters, 49, 34: , 2008. Retrieved from Loyola eCommons, Chemistry: Faculty Publications and Other Works, http://dx.doi.org/ 10.1016/j.tetlet.2008.06.056

This Article is brought to you for free and open access by the Faculty Publications and Other Works by Department at Loyola eCommons. It has been accepted for inclusion in Chemistry: Faculty Publications and Other Works by an authorized administrator of Loyola eCommons. For more information, please contact ecommons@luc.edu. cc) (i) $\Theta$

This work is licensed under a Creative Commons Attribution-Noncommercial-No Derivative Works 3.0 License. (c) 2008 Elsevier 


\section{Graphical Abstract}

To create your abstract, type over the instructions in the template box below.

Fonts or abstract dimensions should not be changed or altered.

Beckmann rearrangement of
cyclotriveratrylene (CTV) oxime: Tandem
Beckmann-electrophilic aromatic addition
Marlon R. Lutz Jr., Matthias Zeller, and Daniel $\mathrm{P}$. Becker
${ }^{a}$ Department of Chemistry, Loyola University Chicago,
6525 North Sheridan Road, Chicago, IL 60626 USA
Department of Chemistry, Youngstown State University,
One University Plaza, Youngstown, OH 44555, USA




\title{
Beckmann rearrangement of cyclotriveratrylene (CTV) oxime: tandem Beckmann-electrophilic aromatic addition
}

\author{
Marlon R. Lutz Jr., ${ }^{\mathrm{a}}$ Matthias Zeller, ${ }^{\mathrm{b}}$ and Daniel P. Becker ${ }^{\mathrm{a} *}$ \\ ${ }^{a}$ Department of Chemistry, Loyola University Chicago, 6525 North Sheridan Road, Chicago, IL 60626 USA \\ ${ }^{b}$ Department of Chemistry, Youngstown State University, One University Plaza, Youngstown, OH 44555, USA
}

\begin{abstract}
The Beckmann rearrangement has been performed on the oxime of cyclotriveratrylene (CTV) with thionyl chloride affording the ring-expanded 10-membered ring amide exclusively in high yield. Modified conditions afford a helical pentcycle derived from an unprecedented tandem Beckmann rearrangement and electrophilic aromatic addition followed by demethylation and tautomerization. (C) 2013 Elsevier Science. All rights reserved
\end{abstract}

The crown-shaped cyclophane cyclotriveratrylene (CTV, 1, hexamethoxy tribenzocyclononene, $){ }^{1}$ has been employed extensively as a scaffold in supramolecular chemistry. This [1.1.1] orthocyclophane is readily prepared from the trimerization of veratryl alcohol in acid and has been extensively studied for its capability of binding a variety of smaller organic and organometallic guests within its bowlshaped cleft. ${ }^{2-4}$ Many clathrates of $\mathrm{CTV}^{5-9}$ and of CTV derivatives ${ }^{5}$ have been structurally characterized including clathrates with anionic C70 dimers. ${ }^{10}$ Thioether derivatives of CTV have recently been employed to immobilize C60 onto gold surfaces, ${ }^{11,}{ }^{12}$ and water soluble CTV derivatives have been developed for biomedical applications including the biological delivery of fullerenes. ${ }^{13}$

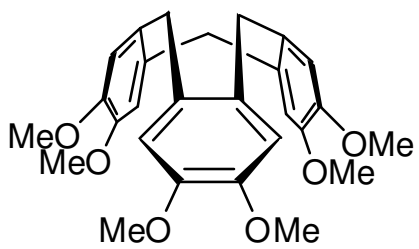

Figure 1. Cyclotriveratrylene, 1 (CTV)

We are interested in new apex-modified derivatives of CTV and we recently reported the isolation of the crown and saddle conformers of CTV oxime, and the kinetics of their interconversion. $^{14} \mathrm{We}$ envisioned performing the
Beckmann rearrangement ${ }^{15,} 16$ on the CTV oxime crown conformer 2 to access the ring-expanded amide and the corresponding amine via reduction to access ring-expanded CTV derivatives that may be functionalized at the apex and are more water soluble. A 9-membered ring azatricyclobenzylene aza-CTV derivative has recently been synthesized in order to assess its pharmacological activity. ${ }^{17}$

We have found that the Beckmann rearrangement performed on pure CTV oxime crown conformer 2 promoted with thionyl chloride in dilute solution at $0^{\circ} \mathrm{C}$ proceeds in essentially quantitative yield (99\%) with isolation by direct crystallization to afford the new 10membered ring amide 3. The ring-expanded amide exists at room temperature exclusively as the crown conformer based on the geminal coupling observed in the proton NMR [4.67 (1H, d, J = 15.0 Hz), $4.44(1 \mathrm{H}, \mathrm{d}, \mathrm{J}=15.3 \mathrm{~Hz}), 3.70$ $(1 \mathrm{H}, \mathrm{d}, \mathrm{J}=15.0 \mathrm{~Hz}), 3.56(1 \mathrm{H}, \mathrm{d}, \mathrm{J}=15.3 \mathrm{~Hz})]$, as pseudorotation of the flexible saddle conformation is know to lead to magnetic equivalence of the geminal benzylic methylene protons. Models suggest that the saddle conformer of the amide derivative may not be able to undergo pseudorotation typical of saddle CTV derivatives despite the larger 10 -membered ring relative to the 9membered ring of CTV because of trans-annular steric interactions. Nevertheless we expect that Beckmann rearrangement of the oxime crown conformer should afford directly the crown conformer of the ring-expanded amide

\footnotetext{
* Corresponding author. Tel.: 773-508-3089; fax: 773-508-3086; e-mail: dbecke3@luc.edu.
} 
with no opportunity for equilibration to the saddle conformer. Interestingly, the crown conformer of the amide is a structurally chiral molecule, although lacking chiral tetrahedral carbon atoms.
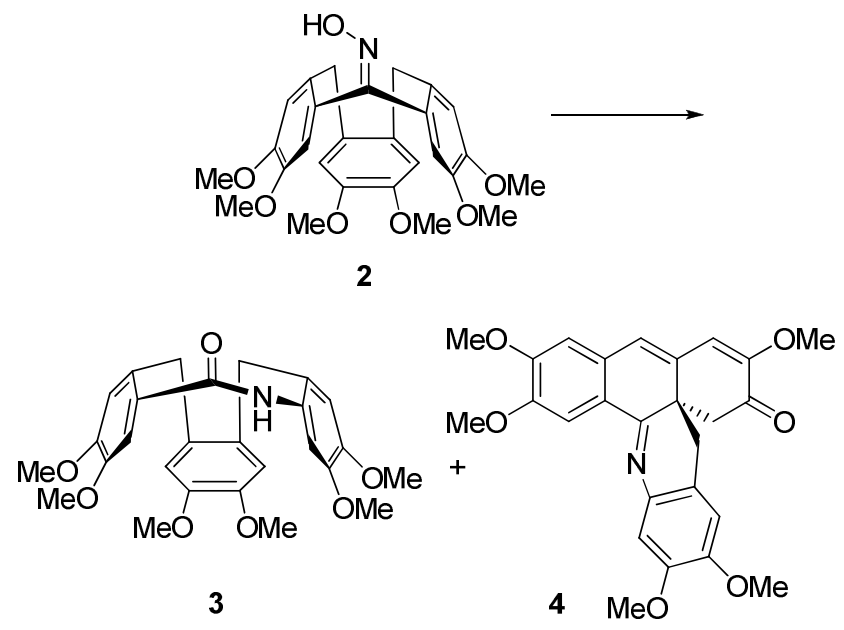

Scheme 1. Beckmann rearrangement of CTV oxime crown conformer to Beckmann amide $\mathbf{3}$ and tandem Beckmann/electrophilic aromatic addition product 4 .

In the course of studying the Beckmann rearrangement of oxime 2 under certain conditions we observed in addition to amide $\mathbf{3}$ the unexpected formation of helical pentacycle 4, resulting from an unprecedented tandem Beckmann rearrangement and intramolecular electrophilic aromatic addition (Scheme 1). Pentacycle $\mathbf{4}$ was produced in good yield $(69 \%)$ when treating oxime $\mathbf{2}$ with thionyl chloride in ether/methylene chloride in a more concentrated solution (1 $\mathrm{M})$, along with a small amount of amide 3 (12\%). The unique structure of $\mathbf{4}$ is consistent with spectroscopic and mass spectral analyses. Only five methyls of the original six are observed by proton and ${ }^{13} \mathrm{C}$ NMR. A new quaternary carbon atom is observed by DEPT at $39.1 \mathrm{ppm}$, and a strong carbonyl stretching vibration is observed at $1681 \mathrm{~cm}^{-1}$ in the infrared spectrum. A molecular weight of 463 is consistent with the $\mathrm{MH}^{+}$ion observed at 448 a.m.u. in the mass spectrum. The structure was ultimately confirmed by single crystal $\mathrm{x}$-ray analysis (Figure 2$){ }^{18}$ The compound shows an unusual helical arrangement of three six-membered rings that are all connected at the central carbon atom C6. The helix effectively performs one full turn around C6, and the thread pitch, as defined by the distance of the terminal atoms C2 and C20 of the helix, is 4.98(3) $\AA$. Classic 4-bond W-type coupling of the protons on $\mathrm{C} 1$ and $\mathrm{C} 7$ is observed for the very rigid pentacyclic system [3.07 (1H, d, J = 16.2 Hz), $2.95(1 \mathrm{H}, \mathrm{d}(\mathrm{br}), \mathrm{J}=16.2$ $\mathrm{Hz}), 2.88(1 \mathrm{H}, \mathrm{d}, \mathrm{J}=15.9 \mathrm{~Hz}), 2.34(1 \mathrm{H}, \mathrm{dd}, \mathrm{J}=15.9,1.8$ $\mathrm{Hz})$.

Curiously, a solution of tandem product $\mathbf{4}$ in methylene chloride is ruby red but turns yellow upon shaking with water. The ruby red color then returns upon shaking with brine, and this color change may be repeated, and may reflect reversible addition of water to the electrophilic enone system or to the imine. In the proposed mechanism for the formation of the pentacyclic tandem Beckmannelectrophilic aromatic addition product (Scheme 2), thionyl chloride activates the oxime for the Beckmann rearrangement and the aryl migrates to the oxime nitrogen (structure 5). The cationic intermediate of the Beckmann rearrangement is represented as a nitrilium cation in structure 6, since strain on the linear triple bond should be minimal in the 10 -membered ring. ${ }^{19}$ Cationic intermediate $\mathbf{6}$ is then attacked by the electron-rich dimethoxyphenyl ring in an electrophilic aromatic substitution process forming two new 6-membered rings and the new quaternary center C6. Intermediate 7 might be expected to undergo demethylation of $\mathrm{O} 1$, but deprotonation occurs instead forming the conjugated triene 8. Demethylation of O6 is apparently acid-catalyzed, along with tautomerization involving proton transfer to $\mathrm{C} 1$, thus affecting hydrolysis of the enol ether and affording the corresponding conjugated ketone of pentacycle $4\left[\mathrm{v}=1662 \mathrm{~cm}^{-1}\right]$.

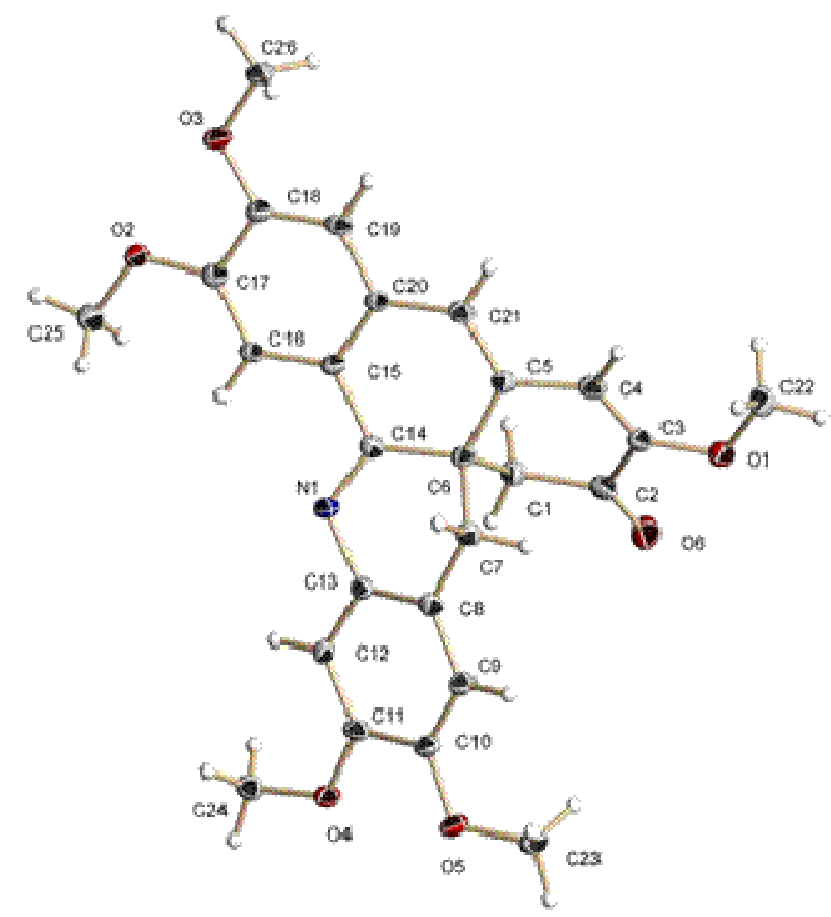

Figure 2. Single crystal x-ray structure of tandem Beckmann/electrophilic aromatic addition product $\mathbf{4}^{18}$

The product distribution in the Beckmann rearrangement is dependent upon the reaction conditions. Careful treatment of a dilute $(0.01 \mathrm{M})$ solution of the oxime crown conformer in ether/methylene chloride at $0^{\circ} \mathrm{C}$ with neat thionyl chloride (38 eq) afforded the Beckmann amide in high yield, as noted above. The same reaction under less dilute $(0.1 \mathrm{M})$ conditions gave $60 \%$ of Beckmann amide 3 and $28 \%$ of the tandem product 4 , whereas addition of neat thionyl chloride to a solution of the oxime at $1.0 \mathrm{M}$ afforded the tandem product $\mathbf{4}$ as the major product in good yield (69\%) along with only $12 \%$ of the Beckmann amide 3 (Table 1). The pronounced effect of concentration may in part reflect cooling efficiency of the exothermic reaction, 
favoring the Beckmann amide product in dilute solution held efficiently at $0^{\circ} \mathrm{C}$, and promoting the tandem electrophilic aromatic addition process at more elevated temperatures. Running the reaction at $-40^{\circ} \mathrm{C}$ resulted in a drop in tandem product 4 to only $6 \%$, whereas higher temperatures $\left(40^{\circ} \mathrm{C}\right)$ favors tandem product $4(48 \%)$ over amide $3(2 \%)$.
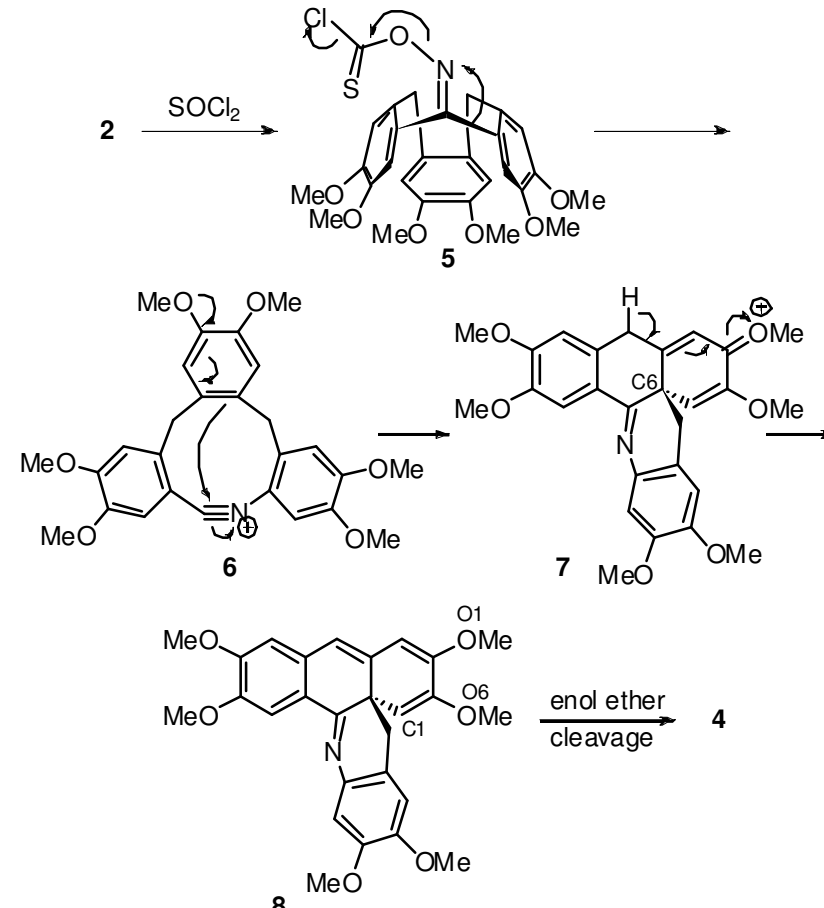

Scheme 2. Proposed mechanism of the tandem Beckmann/electrophilic aromatic addition sequence

Treatment of the oxime 2 with acetic anhydride in xylenes with microwave heating to $200-210^{\circ} \mathrm{C}$ for $1.5 \mathrm{~h}$ under conditions employed by Savarin ${ }^{20}$ to produce isoindoles from oximes gave only $26 \%$ of amide 3 and none of the tandem product 4 . Heating the oxime 2 to $75^{\circ} \mathrm{C}$ for $4 \mathrm{~h}$ with toluenesulfonyl chloride and DMAP in pyridine gave a $56 \%$ isolated yield of amide 3 and none of tandem-derived product 4 . On the other hand, heating the oxime directly in polyphosphoric acid at $140^{\circ} \mathrm{C}$ for 7 min gave pentacycle 4 in $22 \%$ yield with none of the Beckmann amide 3

Table 1. Affect of reaction conditions on product distribution of $\mathrm{SOCl}_{2}$ induced Beckmann rearrangement of crown oxime 2 .

\begin{tabular}{|c|c|c|c|}
\hline $\begin{array}{c}\text { Conc } \\
(\mathrm{M})\end{array}$ & $\begin{array}{c}\text { Temp } \\
\left({ }^{\circ} \mathrm{C}\right)\end{array}$ & $\begin{array}{c}\text { Amide 3 } \\
\text { Yield }(\%)\end{array}$ & $\begin{array}{c}\text { Tandem 4 } \\
\text { Yield }(\%)\end{array}$ \\
\hline 1.0 & 0 & 12 & 69 \\
\hline 0.1 & 0 & 60 & 28 \\
\hline 0.01 & 0 & 99 & 0 \\
\hline 0.1 & -40 & 42 & 6 \\
\hline 0.1 & 40 & 2 & 48 \\
\hline
\end{tabular}

Trans-annular electrophilic addition has been observed previously during the oxidation of CTV with sodium dichromate to give a spiro lactone, ${ }^{21}$ and Schinzer previously employed nucleophilic allylsilanes to intramolecularly trap the cationic Beckmann rearrangement intermediate in the preparation of various heterocycles, ${ }^{22-24}$ but trapping of the cationic Beckmann rearrangement intermediate by electrophilic aromatic addition or substitution has not been previously reported. Thus, this represents a new method for the construction of carboncarbon bonds. Noteworthy is the construction of a congested quaternary carbon atom. In the CTV system, the nucleophilic addition to the cationic Beckmann intermediate is promoted not only by the electron-rich nature of the veratrole moiety but also by the close proximity of the attacking arene carbon and the nitrilium carbon. Our semi-empirical AM1 calculations suggest that the distance between the attacking veratrole carbon and the nitrilium carbon is 3.4 to $3.5 \AA$.

In summary, Beckmann rearrangement of the pure crown conformer of CTV oxime $\mathbf{2}$ affords either the expected ring-expanded amide $\mathbf{3}$, or the helical pentacycle $\mathbf{4}$ which is formed by intramolecular trapping of the cationic Beckmann rearrangement intermediate by an electron-rich arene, or a combination of both products $\mathbf{3}$ and $\mathbf{4}$ depending upon the reagents employed as well as the concentration and temperature of the reaction. The tandem Beckmannelectrophilic aromatic addition sequence is unprecedented, and we are presently exploring the generality of this tandem sequence and its applications in synthesis.

\section{Acknowledgments}

NSF Grant DBI-0216630 is gratefully acknowledged for the $300 \mathrm{MHz}$ NMR obtained through the NSF Major Research Instrumentation Program, and the NSF REU Program (Research Experience for Undergraduates) is gratefully acknowledged for summer financial support for M.L

\section{References}

1. Collet, A. Tetrahedron 1987, 24, 5725-5759.

2. Collet, A. Comprehensive Supramolecular Chemistry. In Atwood, J. L., Davies, J. E. D., MacNicol, D. D., Vögtle, F. and Lehn, J. M., Eds.; Pergamon: Oxford, U.K., 1996; Vol. 6, pp 281-303.

3. Burlinson, N. E.; Ripmeester, J. A. Journal of Inclusion Phenomena 1984, 4, 403-409.

4. Steed, J. W.; Zhang, H.; Atwood, J. L. Supramolecular Chemistry 1996, 1, 37-45.

5. Ahmad, R.; Hardie, M. J. Supramolecular Chemistry 2006, 1, 29-38.

6. Caira, M. R.; Jacobs, A.; Nassimbeni, L. R. Supramolecular Chemistry 2004, 5, 337-342.

7. Huber, J. G.; Dubois, L.; Desvaux, H.; Dutasta, J.; Brotin, T.; Berthault, P. Journal of Physical Chemistry A 2004, 44, 96089615. 
8. Ahmad, R.; Dix, I.; Hardie, M. J. Inorg. Chem. 2003, 7, 21822184.

9. Travis Holman, K.; William Orr, G.; Atwood, J. L.; Steed, J. W. Chemical Communications (Cambridge) 1998, 19, 21092110.

10. Konarev, D. V.; Khasanov, S. S.; Vorontsov, I. I.; Saito, G.; Antipin, M. Y.; Otsuka, A.; Lyubovskaya, R. N. Chemical Communications (Cambridge, United Kingdom) 2002, 21, 2548-2549.

11. Zhang, S.; Palkar, A.; Fragoso, A.; Prados, P.; de Mendoza, J.; Echegoyen, L. Chemistry of Materials 2005, 8, 2063-2068.

12. Zhang, S.; Echegoyen, L. Comptes Rendus Chimie 2006, 7-8, 1031-1037.

13. Rio, Y.; Nierengarten, J. Tetrahedron Lett. 2002, 24, 43214324.

14. Lutz Jr., M. R.; French, D. C.; Rehage, P.; Becker, D. P. Tetrahedron Letters 2007, 36, 6368-6371.

15. Donaruma, L. G.; Heldt, W. Z. Org. Reactions (Arthur C.Cope, editor) 1960, 1-156.
16. Conley, R. T.; Ghosh, S. Mechanisms of Molecular Migrations 1971, 197-308.

17. Hayashi, K.; Inoue, S.; Shimizu, H.; Kobayashi, A.; Ishizaki, M.; Matsuoka, Y.; Nishitani, K.; Hara, H. Heterocycles 2005, $1,1-4$.

18. Lutz Jr., M. R.; Zeller, M.; Becker, D. P. Acta Crystallographica, Section E, 2007, E63, o3857-o3858.

19. Turner, R. B.; Jarrett, A. D.; Goebel, P.; Mallon, B. J. J. Am. Chem. Soc. 1973, 3, 790-792.

20. Savarin, C. G.; Grise, C.; Murry, J. A.; Reamer, R. A.; Hughes, D. L. Org. Lett. 2007, 6, 981-983.

21.Lutz Jr., M. R.; Zeller, M.; Becker, D. P. Acta Crystallographica, Section E, 2007, E63, o4390-04391.

22. Schinzer, D.; Bo, Y. Angewandte Chemie 1991, 6, 727-8; Angew. Chem., Int. Ed. Engl., 1991, 30, 687-8.

23. Schinzer, D.; Langkopf, E. Synlett 1994, 5, 375-377.

24. Schinzer, D.; Abel, U.; Jones, P. G. Synlett 1997, 5, 632-634. 